\title{
Structure of Cyclonic Precipitation in the Northern Pacific Storm Track Measured by GPM DPR
}

\author{
AOQI ZHANG AND YILUN CHEN \\ School of Earth and Space Sciences, University of Science and Technology of China, Hefei, and School of Atmospheric \\ Sciences, Sun Yat-sen University, and Southern Marine Science and Engineering Guangdong Laboratory (Zhuhai), \\ Zhuhai, China \\ XIANGDONG ZHANG \\ International Arctic Research Center, University of Alaska Fairbanks, Fairbanks, Alaska \\ QIONG ZHANG \\ Department of Physical Geography, Stockholm University, Stockholm, Sweden \\ YUNFEI FU \\ School of Earth and Space Sciences, University of Science and Technology of China, Hefei, China
}

(Manuscript received 24 July 2019, in final form 1 December 2019)

\begin{abstract}
Despite the long existence of theoretical studies, few statistical studies of precipitation characteristics on the northern Pacific storm track have been reported due to lack of observation. Using data from GPM DPR and ERA-Interim, we examined the precipitation features of extratropical cyclones in the northern Pacific stormtrack region. Extratropical cyclones were classified into four categories including developing, mature, dissipating, and short-term based on their life stages. Our results show that extratropical cyclones of all categories had a "comma" rainband and precipitation mostly occurred to the east of the cyclonic center. The extratropical cyclones promote precipitation to the east of their centers, but suppress precipitation to the west. Precipitation to the east of the extratropical cyclones had larger and more condensed droplets, a stronger intensity, and a higher rain top than the local seasonal average, while the opposite characteristics were seen to the west. Our results suggest that the different types of vertical air motion and moisture content in these two regions induced by the frontal structure of extratropical cyclones play important roles in the different impact of extratropical cyclones. Furthermore, the different life stages of extratropical cyclones had different degrees of impact on precipitation: the highest impact in the developing stage, followed by the mature stage, and the weakest impact in the dissipating stage.
\end{abstract}

\section{Introduction}

Extratropical cyclones (ECs) in the boreal winter most commonly occur in the northern Pacific stormtrack region (Chang and Fu 2002; Hoskins and Hodges 2005; Shaw et al. 2016). With strong vertical and horizontal exchanges of heat, water vapor, and momentum, the ECs in this region play an important part in the global atmospheric circulation and energy budget (Bengtsson et al. 2006; Held et al. 1989; O'Gorman 2010). Furthermore, the storm track of ECs has a close

Corresponding author: Yunfei Fu, fyf@ustc.edu.cn and complex interaction with regional and global climate disturbances (Lau 1988; Hoskins and Valdes 1990; Chang et al. 2012; Graff and LaCasce 2012; Kidston et al. 2015; Lehmann and Coumou 2015). For instance, based on numerical simulations, Graff and LaCasce (2012) pointed out that the intensity and location of storm track respond to changes in both the mean sea surface temperature (SST) and SST gradients. Using regression analyses, Lehmann and Coumou (2015) showed that the intensity of midlatitude storm-track activities influences the hot, cold, dry, and wet extremes.

Although most of the studies have focused on the climate impact or interdecadal variations of storm track 
(Johnson et al. 1998; Yin 2005; Chang and Fu 2002, 2003; Bengtsson et al. 2006; Harvey et al. 2015; Adler et al. 2017), the structural features of ECs associated with the storm track still received widespread attention (Bjerknes 1919; Shapiro and Keyser 1990). The polar front theory, which is closely related to the structure of ECs, was first proposed by the Bergen school (Bjerknes 1919; Bjerknes and Solberg 1921, 1922). Bjerknes (1919) proposed a flow model for ECs and showed that every EC has two lines of convergence that are actually the cold and warm fronts bordering the warm area of the cyclone. Bjerknes and Solberg (1922) further presented the frontal cyclone model describing the variation of the inner fronts during the life cycle of ECs. Each EC experiences four life stages of incipiency, rapid development, maturity, and dissipation, and the most well-known structure of the occluded front occurs at the mature stage. By combining the results during the Alaskan Storm Program (ASP) and the Experiment on Rapidly Intensifying Cyclones over the Atlantic (ERICA), Shapiro and Keyser (1990) modified the model of the life cycle of the marine extratropical frontal cyclone. Specifically, they pointed out the T-bone shape of fronts during the rapid developing stage instead of the continuous fronts in the Bergen theory.

The frontal structure of ECs affects the precipitation of the cyclone, and the position of the fronts often corresponds to the position of the precipitating clouds (Palmen and Newton 1969). Hobbs et al. (1975) classified the mesoscale rainbands in ECs into six categories (warm frontal, warm sector, cold frontal-wide, cold frontal-narrow, wave-like, postfrontal) according to their position in the frontal structure. Carlson (1991) further summarized that most of the precipitating clouds of ECs belong to either the cold or warm frontal system. Therefore, determination of the distribution and detailed features of EC precipitation will help us to better understand the structure of ECs and provide a reference for the cloud and precipitation modules in the EC model. However, despite the long existence of theoretical studies, observations of the EC precipitation, especially carried out over a long period of time in the northern Pacific storm track are still lacking due to the geographic location of this region.

The existing research on the cyclonic precipitation in the northern Pacific storm track mainly relies on reanalysis data as well as a few observations of marine observational experiments and ground-based radar, which restrict the detailed statistical study of precipitation features. For instance, using ground-based radar, Houze et al. (1976) compared six types of rainbands (as seen above) in 11 ECs and indicated that these rainband types occur rather generally. Mace (2010) analyzed the properties of clouds in the Atlantic storm track through A-Train observations. Based on data from the Global Precipitation Climatology Project (GPCP), Hawcroft et al. (2012) reported that more than $90 \%$ of precipitation in the storm-track region comes from ECs. Using reanalysis data, Pfahl and Sprenger (2016) studied the relationship between the intensity of ECs and precipitation, pointing out that stronger precipitation occurs in more intense cyclones but the correlation coefficient reduces after the time of maximum intensity. However, all of these data are highly restricted in statistically revealing the precipitation structures, and we need to introduce more robust observations to study the threedimensional structures of cyclonic precipitation in the northern Pacific storm-track region.

In the preset work we used the precipitation products from the Global Precipitation Measurement (GPM) Mission Dual-Frequency Precipitation Radar (DPR) instrument to characterize the precipitation features in ECs in the northern Pacific storm track. Being the first onboard dual-frequency precipitation radar instrument, the GPM DPR provides an excellent opportunity to study the structural characteristics of precipitation in mid- and high-latitude regions (Hou et al. 2014). We aim to reveal the precipitation features under the dynamic background of ECs and validate the previous cyclonic theories using DPR observations.

\section{Data and methods}

We used precipitation data from the GPM DPR instrument, which was co-designed by the Japan Aerospace Exploration Agency (JAXA) and the National Institute of Communication Technology (NICT). The DPR consists of a Ku-band precipitation radar (KuPR, 13.6 GHz) and a Ka-band precipitation radar (KaPR, 35.5 GHz) covering the Earth from $65^{\circ} \mathrm{S}$ to $65^{\circ} \mathrm{N}$ (Hou et al. 2014). The KuPR has only one scan mode (normal scan) with a minimum detectable reflectivity of $14.5 \mathrm{dBZ}$, whereas the KaPR has two scan modes (matched scan and highsensitivity scan) with minimum detectable reflectivities of 16.7 and $10.2 \mathrm{dBZ}$, respectively (Hamada and Takayabu 2016). Based on the different responses of the KuPR and KaPR to atmospheric hydrometeors, the GPM has developed dual-frequency algorithms for precipitation information (e.g., rain type, storm-top height, droplet size distribution, and rain rate; Iguchi et al. 2012). We used the GPM dual-frequency product 2ADPR from 4-yr (2014-18) winter seasons (DJF) in the northern Pacific storm-track region $\left(30^{\circ}-70^{\circ} \mathrm{N}, 140^{\circ} \mathrm{E}-120^{\circ} \mathrm{W}\right)$.

We used the $1^{\circ} \times 1^{\circ}$ grid mean sea level pressure (MSLP) from the European Centre for Medium-Range 

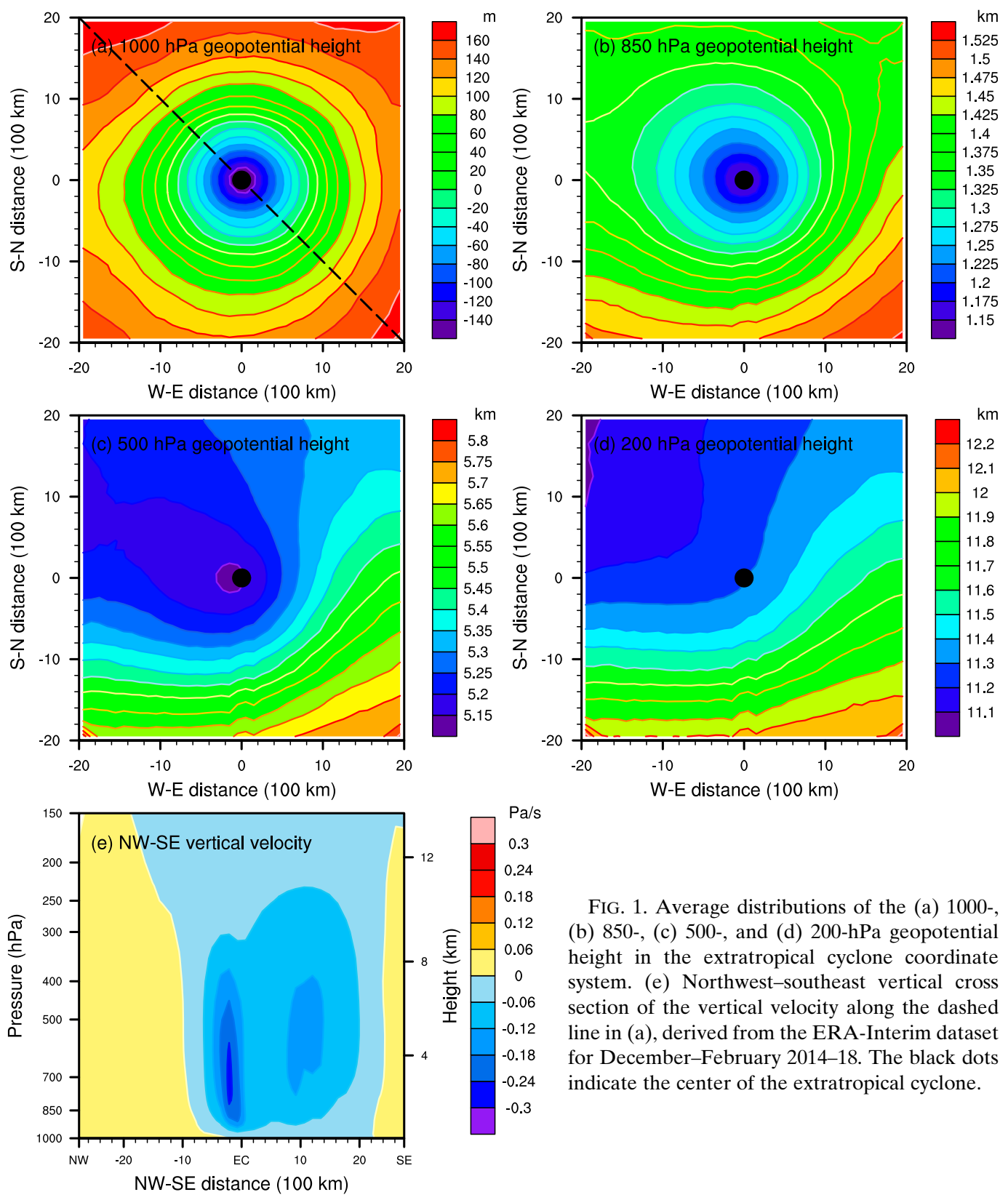

FIG. 1. Average distributions of the (a) 1000-, (b) 850-, (c) 500-, and (d) 200-hPa geopotential height in the extratropical cyclone coordinate system. (e) Northwest-southeast vertical cross section of the vertical velocity along the dashed line in (a), derived from the ERA-Interim dataset for December-February 2014-18. The black dots indicate the center of the extratropical cyclone.

Weather Forecast interim reanalysis (ERA-Interim) dataset to calculate the location and movement of ECs in the northern Pacific storm track. The ERA-Interim dataset has been widely used in atmospheric research (Dee et al. 2011; Zhang et al. 2018). ECs were identified and tracked using the method of Pinto et al. (2005), which consists of four steps listed below. Similar identification methods were used in many other studies (e.g., Romanić et al. 2016).

1) Calculate the Laplacian operator of the MSLP $\nabla_{p}^{2}$ and the local minimum of the MSLP.
2) Within a 500-km distance from the MSLP minimum, calculate the average $\nabla_{p}^{2}$, then eliminate the MSLP minima of the average $\nabla_{p}^{2}<50 \mathrm{~Pa} \mathrm{~km}^{-2}$.

3) Within each radius of $500 \mathrm{~km}$, retain at most one MSLP minimum. If there are two or more MSLP minima, only the strongest minimum (with the largest average $\nabla_{p}^{2}$ ) is retained. These retained MSLP minima are the identified EC centers.

4) Successive EC centers are connected if they occur within a specific search area that depends on the trajectory of the previous EC. These isolated EC centers were also eliminated. 
Over four boreal winters, we identified 539 valid EC tracks in the study region. We defined a new EC coordinate system to facilitate the statistics. In this coordinate system, the origin indicates the center of the EC, the $x$ axis represents the east-west direction and the $y$ axis represents the south-north direction. For every 2ADPR precipitation pixel, if there is at least one EC track at the precipitating time, we would calculate the positions of the EC centers at that time by linear interpolation and then recalibrate the 2ADPR pixel to the nearest EC coordinate system. Consistent with the work of Hawcroft et al. (2012), we found that more than $90 \%$ of the precipitation pixels were within $1500 \mathrm{~km}$ of the center of the EC. We calculated the average nearsurface rain rate, near-surface rain rate anomaly relative to local seasonal average, and storm-top height anomaly relative to local seasonal average within the EC coordinate system. In our study, we did not use nonprecipitation 2ADPR pixels in calculating average precipitation. The calculation method of local seasonal average near-surface rain rate (storm top height) contains two steps as following. First, we divided the study region into $1^{\circ} \times 1^{\circ}$ grids. Then within each grid, the local seasonal average of near-surface rain rate was obtained as the average near-surface rain rate for 4-yr winter seasons (DJF).

To investigate the impact of EC life cycle on precipitation features of ECs, ECs were classified into four categories based on their life stage. These four categories are developing ECs, mature ECs, dissipating ECs, and short-term ECs. The classification method is described as follows. First, ECs with lifetime shorter than $24 \mathrm{~h}$ were identified as short-term ECs. Then, for each non-short-term EC track, we established a time series of cyclonic MSLP at a time resolution of $6 \mathrm{~h}$. Based on this time series, we found out the time with minimum MSLP $P_{\min }$ of EC. This time and its nearby time in the series with MSLP less than $3 \mathrm{hPa}+P_{\min }$ were classified into mature ECs. At last, for each EC track, ECs that happened before the mature stage were classified as developing ECs and those after the mature stage were classified as dissipating ECs.

In addition, we also used the geopotential height, temperature, vertical velocity, and specific humidity from the ERA-Interim dataset to provide relevant environmental information for precipitation caused by ECs. All of these parameters were studied statistically based on the defined EC coordinate system. In addition, we also matched the nearest grid of ERA-Interim information (within $\pm 3 \mathrm{~h}$ ) to the 2ADPR precipitation pixels to obtain the environmental information of EC precipitation.

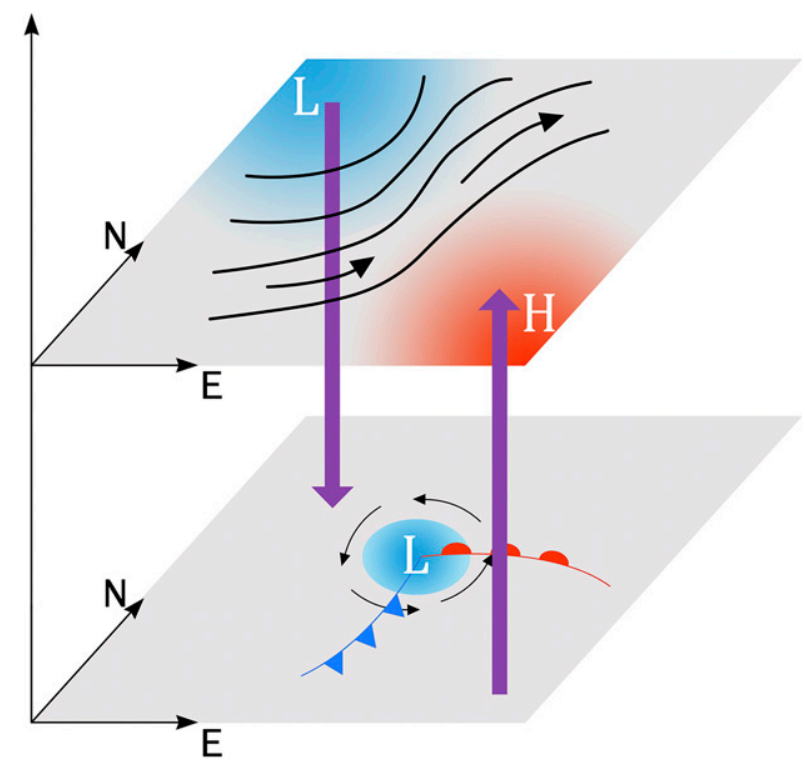

FIG. 2. Sketch of the extratropical cyclone (blue, depression; red, high pressure region; purple vectors, upward/downward motion; black lines, isobaric lines; black vectors, horizontal flow).

\section{Results}

\section{a. Overall atmospheric circulation}

Tropical cyclones are generally much stronger than ECs and the low-level convergence field of tropical cyclones can extend from the Earth's surface to more than $14 \mathrm{~km}$ (Houze et al. 2007; Li et al. 2013). However, the low-level circulation for ECs is very different from the circulation at mid and high levels (Carlson 1991). The range of ECs can reach more than $1400 \mathrm{~km}$, whereas the range of tropical cyclones is generally $\sim 500 \mathrm{~km}$ (Hawcroft et al. 2012).

Figures $1 \mathrm{a}-\mathrm{d}$ show the average distribution of the geopotential height at different pressure levels in the EC coordinate system. The contours of geopotential height appeared as concentric circles in the lower troposphere, with the lowest geopotential height in the center of the EC (Figs. 1a,b). This indicated that the center of the EC has the lowest air pressure in the lower troposphere with significant convergence around this center. As the pressure, which is affected by the atmospheric baroclinicity, increased (Figs. 1c,d), the center of lowest geopotential height gradually spread to the northwest, indicating movement of the depression. The pressure field in the mid- to upper troposphere was low in the northwest and high in the southeast. The changes in the pressure field in the upper troposphere naturally resulted in a change in horizontal flow, further influencing the vertical flow of air around the EC. The cross section of the vertical velocity $\left(\mathrm{Pa} \mathrm{s}^{-1}\right)$ along the 

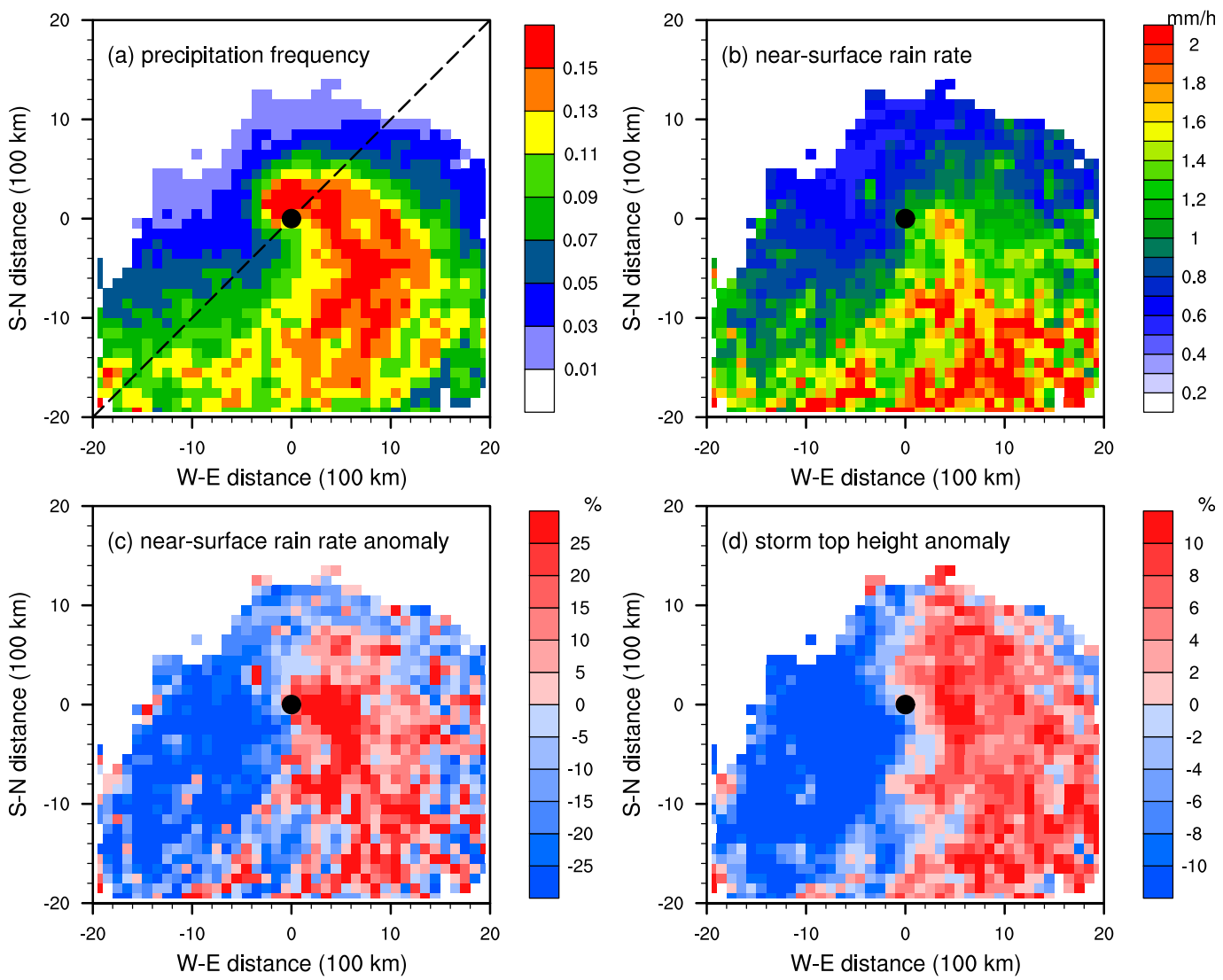

FIG. 3. The distribution of (a) precipitation frequency, (b) near-surface rain rate, (c) near-surface rain rate anomaly relative to the local seasonal average, and (d) storm-top height anomaly compared with the local seasonal average at each $100 \mathrm{~km} \times 100 \mathrm{~km}$ grid in the EC coordinate system, derived from 2ADPR for December-February 2014-18. The black dots indicate the EC center.

northwest-southeast line in Fig. 1a (dashed line) is shown in Fig. 1e. It can be clearly seen that, in addition to the center of upward motion in the center of the EC, there was another center of upward motion $1000 \mathrm{~km}$ southeast of the center, whereas the corresponding position northwest of the center of the EC showed downward motion.

To give a better understanding of the environmental field of the EC, Fig. 2 shows a sketch of a typical threedimensional structure (Bjerknes 1919; Carlson 1991; Palmen and Newton 1969). There are distinct fronts in the structure of ECs, which are related to significant differences in the pressure field in the upper and lower troposphere. A cold front extends from the southwest to the center of the EC and a warm front extends from the center to the east of the EC. The area surrounded by these two fronts, which corresponds to a warm conveyor belt in the EC structure (Schultz 2001; Field and Wood 2007; Schultz and Vaughan 2011; Schemm and Wernli 2014), is a region of upward motion and promotes the generation of clouds and precipitation. By contrast, the downward motion in the northwest is associated with a dry airstream with EC and suppresses clouds and precipitation (Schultz and Vaughan 2011).

\section{b. Precipitating features}

To validate these suggestions about the precipitation features of ECs, we recalibrated the 2ADPR precipitation pixels to the EC coordinate system and studied the three-dimensional structural features of EC precipitation. Figure 3 shows the average distribution of the precipitation frequency, near-surface rain rate, and storm-top height in the EC coordinate system. It is well known that the rainband of tropical cyclones usually occurs on the eyewall and spiral rain belts (Houze et al. 2007). However, the precipitation related to ECs is very different (Fig. 3a). The distribution of precipitation frequency showed as a comma shape and was quite similar to the shape of the comma cloud system, both of which are affected by the large-scale baroclinic system (Carlson 1980). The "comma" rainband was located in the eastern part of the EC coordinates with precipitation 

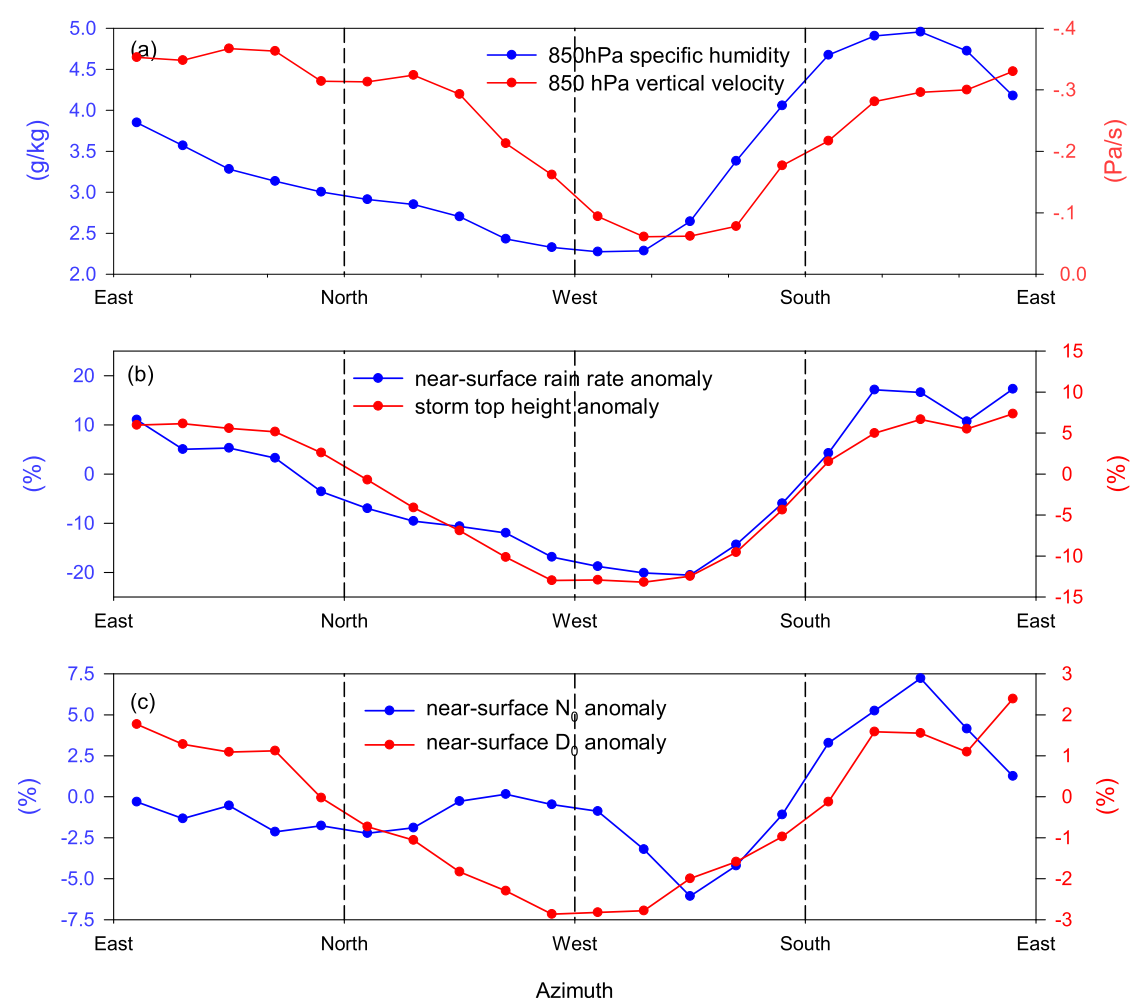

FIG. 4. The azimuthal distributions of (a) 850-hPa specific humidity and vertical velocity, (b) near-surface rain rate anomaly and storm-top height anomaly relative to the local seasonal average, and (c) near-surface droplet concentration $N_{0}$ anomaly and near-surface effective particle diameter $D_{0}$ anomaly relative to the local seasonal average. Specifically, samples should be within 2000-km distance of the EC center.

frequency of $\sim 0.15$. This validates the impact of fronts on precipitation related to ECs (Carlson 1991).

Figure $3 b$ shows the average distribution of the nearsurface rain rate in the EC coordinate system. Because the storm-track region is located in the high-latitude ocean, the average rain rate was generally $<2.5 \mathrm{~mm} \mathrm{~h}^{-1}$, although there were still apparent regional differences in the distribution of the near-surface rain rate. The near-surface rain rate in the south of the EC was significantly larger than that in the north, which is suggested to be the result of the warmer sea surface temperature and moister atmospheric layer within the southern part of the EC structure. The near-surface rain rate was greater in the east than the west, which may be related to the frontal structure of the EC. To eliminate the impact of geographical location, we calculated the distribution of the near-surface rain rate and storm-top height anomalies relative to the local seasonal average (Figs. 3c,d). The near-surface rain rate and storm-top height in the east of the ECs were $20 \%$ and $8 \%$ greater, respectively, than the local average, showing that the EC promotes precipitation to the east. By contrast, the precipitation was depressed in the west of the ECs, although ECs were previously thought to promote heavy precipitation. Compared with the local seasonal average, the precipitation was weaker and lower in the west of the ECs. Our results are consistent with the cloud belt model of marine mature frontal cyclones (Shapiro and Keyser 1990) and further revealed the suppression of precipitation in the west of EC.

For better understanding the variant impact of EC structures on precipitation, the azimuthal distributions of rain rate, storm-top height, droplet size distribution (DSD) parameters, and relevant environmental parameters were studied within $2000 \mathrm{~km}$ of the center of the ECs. The water vapor content and the vertical velocity are generally considered to have a large impact on precipitation (Chen and Fu 2018; Zhang and Fu 2018). Considering the storm-top height of precipitation, Fig. 4a shows the azimuthal distributions of specific humidity and vertical velocity at the $850-\mathrm{hPa}$ pressure level. Since only the values of precipitation time were accounted, the $850-\mathrm{hPa}$ air mass showed uplift with specific humidity more than $2 \mathrm{~g} \mathrm{~kg}^{-1}$ at each direction of ECs. The average upward vertical velocity peaked at the northeast of the EC with a value of $0.35 \mathrm{~Pa} \mathrm{~s}^{-1}$. By 

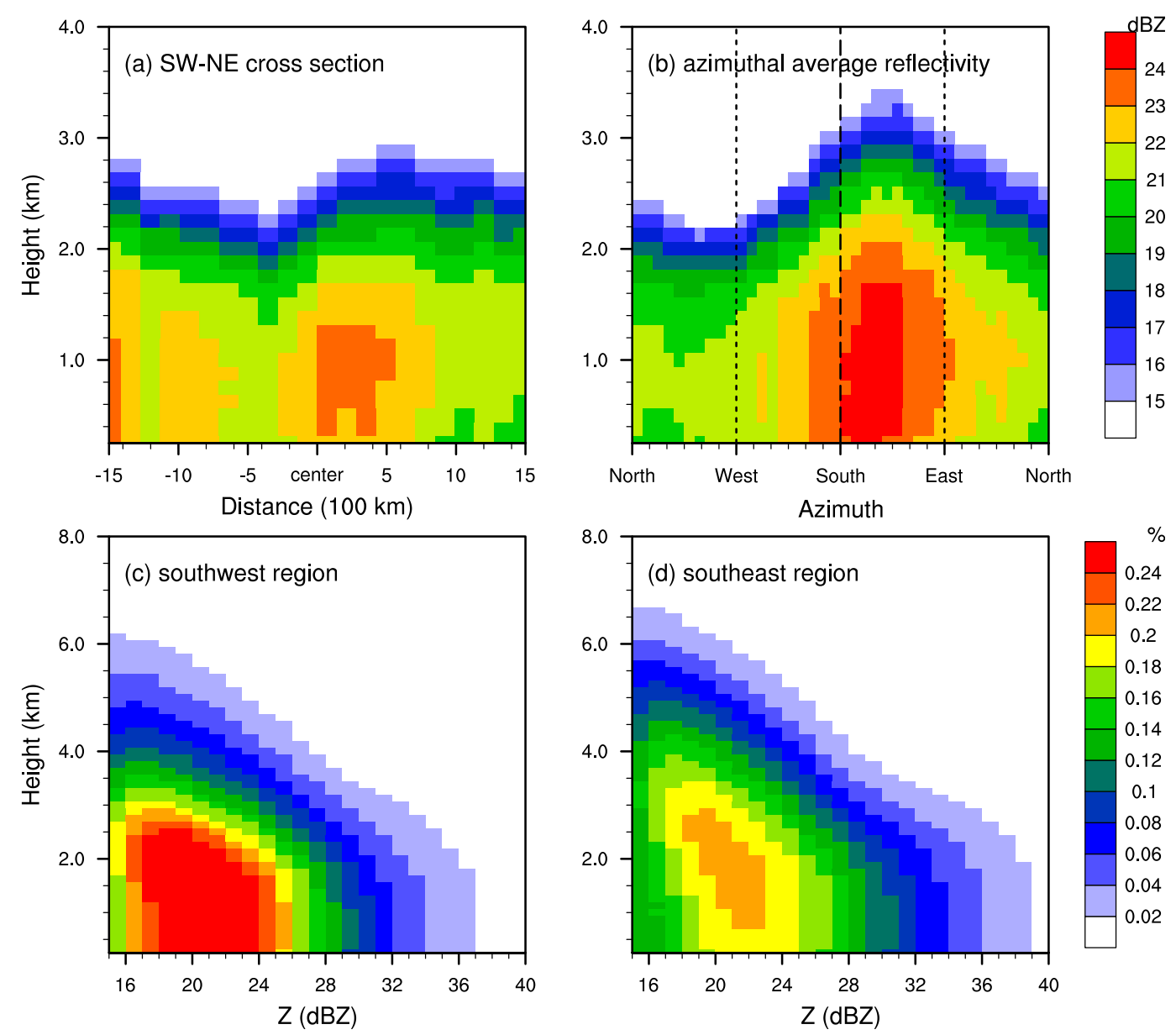

FIG. 5. The (a) southwest-northeast vertical cross section (along the dashed line in Fig. 3a), (b) azimuthal distribution of Ku-band reflectivity, and (c),(d) contoured frequency by altitude diagram of the Ku-band reflectivity for precipitation in the southwest and southeast region of the EC center.

contrast, the peak of the 850 -hPa specific humidity appeared $45^{\circ}$ southeast of the ECs with a value of $5.0 \mathrm{~g} \mathrm{~kg}^{-1}$. It is suggested that this different azimuthal peak of specific humidity is also related to the locations of conveyor belts in the EC structure (Schultz and Vaughan 2011; Schemm and Wernli 2014). The warm conveyor belt is located to the southeast of the ECs, which corresponds to the azimuthal peak of moisture. The dry airstream is located to the northwest of ECs, which corresponds to the azimuthal regions of low humidity.

Figure $4 \mathrm{~b}$ shows the azimuthal distribution of nearsurface rain rate and storm-top height anomalies relative to their local seasonal average. The distribution of the near-surface rain rate was highly consistent with that of the storm-top height. The precipitation was more intense and higher than the local seasonal average in the east of the ECs, consistent with the results shown in Fig. 3. The southerly moister air brought to this area by the cyclonic circulations, along with the upward motion, promoted the development of precipitation. Due to the opposite reason, the precipitation was weaker in the west of ECs, with a lower rain top than the local seasonal average.

It is well known that the rain rate is co-controlled by the concentration and diameter of rain droplets (Iguchi et al. 2012). These DSD parameters reflect the microphysical features of precipitation and can provide us an excellent opportunity to study the dynamical and microphysical process of precipitation (Ulbrich and Atlas 2007; Cao et al. 2008). The dual-frequency retrieval of GPM DPR first provides the space-based DSD profiles, which lays a good foundation for microphysical studies (Hou et al. 2014). We hence calculated the azimuthal distribution of the near-surface droplet concentration $N_{0}$ anomaly and the near-surface effective particle diameter $D_{0}$ anomaly relative to the local seasonal average (Fig. 4c). The azimuthal distributions of the $N_{0}$ anomaly and $D_{0}$ anomaly showed very different 

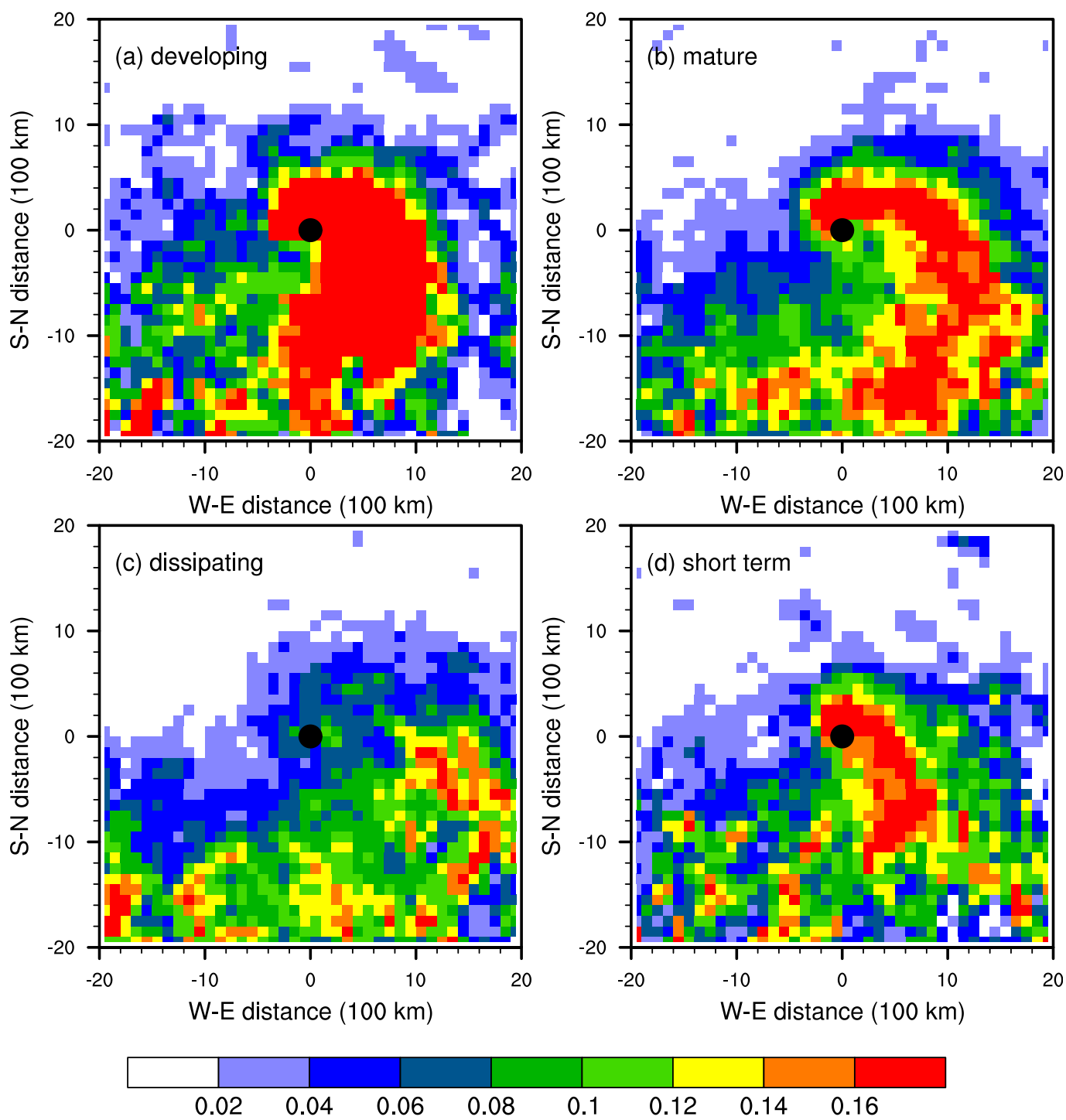

FIG. 6. The distribution of precipitation frequency for (a) developing ECs, (b) mature ECs, (c) dissipating ECs, and (d) short-term ECs at each $100 \mathrm{~km} \times 100 \mathrm{~km}$ grid in the EC coordinate system, derived from 2 ADPR for December-February 2014-18. The black dots indicate the EC center.

features. The $N_{0}$ of precipitation was similar to the local seasonal average in the northwest and northeast of the EC, while it was $4 \%$ lower in the southwest and $4 \%$ higher in the southeast. We suggest it is because the lowlevel air is much moister to the southeast than to the southwest of the EC (Fig. 3a). The $D_{0}$ of precipitation was $2 \%$ larger than the local seasonal average in the east, whereas it was $2 \%$ smaller in the west of the EC. This is consistent with the azimuthal distribution of 850hPa vertical velocity (Fig. 4a). The droplets in the east of ECs need to grow larger before falling as a result of the strong upward flow (Langmuir 1948).

These results revealed the horizontal distributions of EC precipitation in the Pacific storm track. We further analyzed the vertical structure of EC precipitation based on the Ku-band reflectivity profiles provided by the 2ADPR data (Fig. 5). Figure 5a shows the cross section of reflectivity from the southwest to northeast of the ECs. The echo intensity and storm-top height had two peaks, which appeared at the most southwest part in the cross section and $500 \mathrm{~km}$ northeast of the center, respectively. This bimodal structure of the cross section may be resulted from the collective effect of latitude and cyclonic fronts. Figure 5b shows the azimuthal distribution of the Ku-band reflectivity in the EC coordinate system. Consistent with the earlier results, the echoes were highest and strongest in the southeast of the ECs. We further analyzed the 

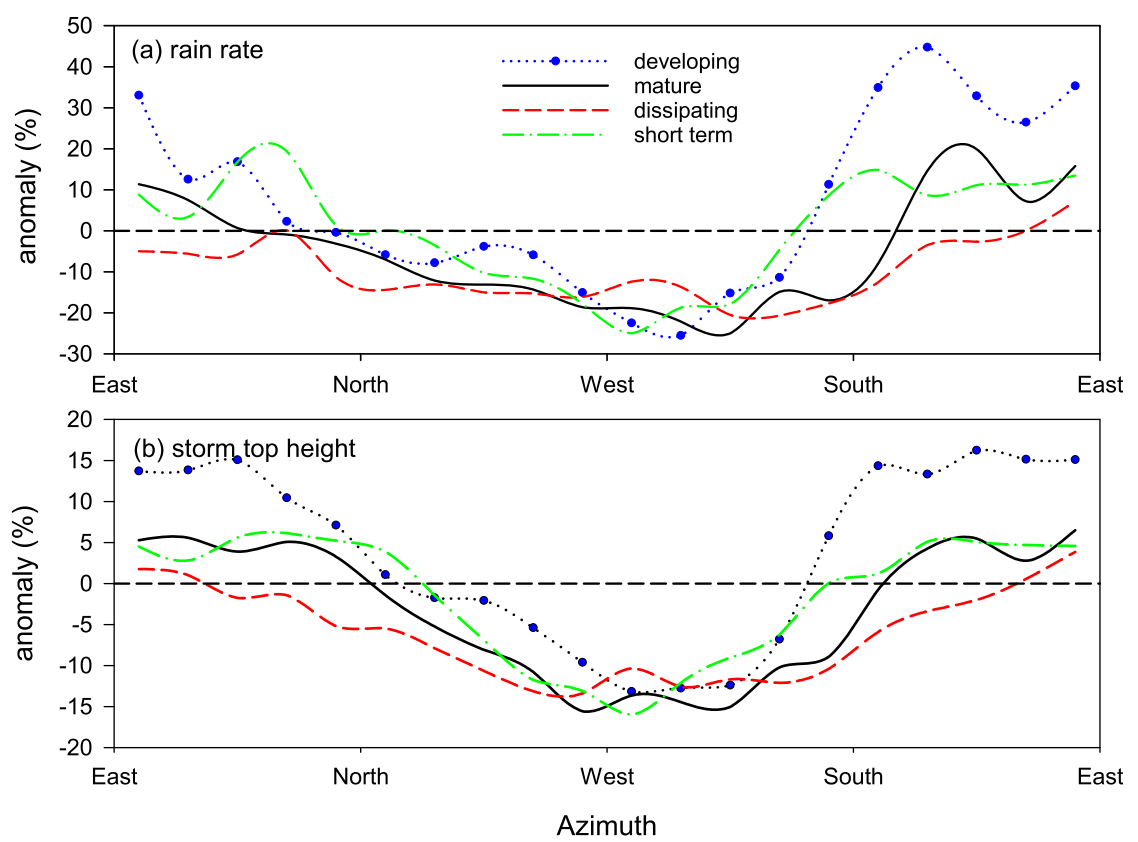

FIG. 7. The azimuthal distributions of (a) near-surface rain rate anomaly and (b) storm-top height anomaly relative to the local seasonal average for ECs at different life stages.

contoured frequency by altitude diagrams (CFAD) of the Ku-band reflectivity in the southwest and southeast of the ECs (Figs. 5c,d). These two regions were at the same latitudes but had quite different vertical velocity and specific humidity. The Ku-band echoes in the southwest of the ECs were much more concentrated in the area below $3 \mathrm{~km}$ and $<24 \mathrm{dBZ}$. This further validated the different impact of vertical air motion on precipitation in the EC structure.

\section{c. Life cycle effects}

The above studies gave the atmospheric circulation and precipitating features of ECs from the perspective of overall average. However, due to the multiple stages of an EC's life process, the structure characteristics of an EC vary considerably over its life time (Bjerknes and Solberg 1922; Shapiro and Keyser 1990). Thus, we must take into account the life cycle effects of ECs on the precipitating features of ECs. Here, we divided ECs into four categories: developing, mature, dissipating, and short-term ECs according to the variation of pressure of cyclonic centers.

Figure 6 shows the distribution of precipitation frequency for four EC categories in the EC coordinate system. The distribution of each category showed a comma shape, consistent with the conceptual model of the life cycle of the marine extratropical frontal cyclone proposed by Shapiro and Keyser (1990). The head of the comma rainband located to the northeast of the EC center (Fig. 6). Precipitation of all categories tended to be distributed on the east side, the moving direction of ECs, which is related to the inner fronts. In addition to the commonality, there were also differences in the distribution of precipitation frequency of four categories. Precipitation frequency corresponding to the developing stage was the largest, followed by the mature stage, and was the smallest for the dissipating stage, indicating the tendency of EC precipitation. The precipitation frequency of the dissipating stage was the most dispersed, showing the weakest influence of ECs at this stage (Fig. 6c). In addition, the comma rainband of short-term ECs (Fig. 6d) was much smaller than the others, indicating that shortterm ECs have the smallest influential ranges.

To qualify the differences of precipitating features for ECs at different stages, we calculated the azimuthal distributions of near-surface rain rate anomaly and storm-top height anomaly relative to local seasonal average for ECs of each category (Fig. 7). The lines of near-surface rain rate anomaly showed great consistency with that of storm-top height anomaly, and the tendencies of azimuthal lines of the four categories were also the same. On the west of the EC, precipitation was weaker with lower storm-top height relative to the seasonal average, indicating that EC restrains precipitation development there; and it was just the opposite on the east of the EC. There were numerical differences in the peaks of the near-surface rain rate anomaly and stormtop height anomaly for ECs of different life stages. On 

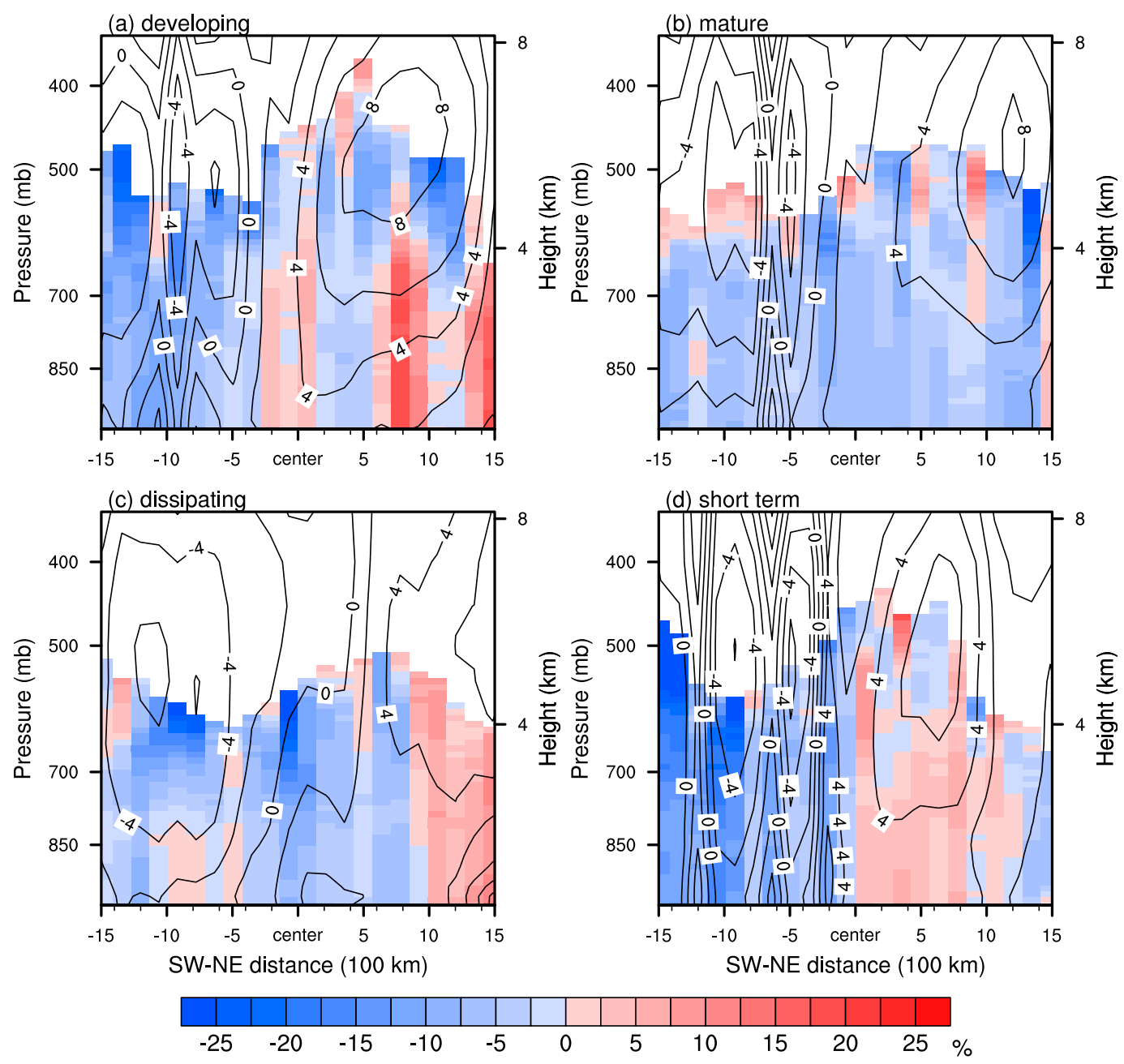

FIG. 8. The southwest-northeast vertical cross section of droplet concentration $N_{0}$ anomaly for (a) developing ECs, (b) mature ECs, (c) dissipating ECs, and (d) short-term ECs. The contoured lines indicate the potential temperature anomaly $(\mathrm{K})$ relative to the local seasonal average.

the east of the ECs, the near-surface rain rates of developing, mature, and dissipating stages were $30 \%, 15 \%$, and $5 \%$ larger than the local seasonal average; and the storm-top heights were respectively $12.5 \%, 8 \%$, and $4 \%$ higher than the local seasonal average. Hence it was indicated that the promotion of $\mathrm{EC}$ on precipitations to its east side becomes weaker as the life stage of EC increases. Furthermore, it was revealed the life cycle impact of ECs is very different from that of clouds, which exerts the strongest promotion on precipitation at mature stage of clouds (Zhang and Fu 2018).

Similarly, we calculated the vertical cross section of droplet concentration $N_{0}$ anomaly and effective droplet size $D_{0}$ anomaly along the southwest-northeast cross section of the EC coordinate system (Figs. 8 and 9). The vertical cross section of the potential temperature anomaly was also shown as contoured lines. For EC precipitation of all categories, the potential temperature anomaly showed a positive center to the northeast of the EC (Figs. 8 and 9), which corresponds to the head of the comma rainband (Fig. 6). The positive anomaly of potential temperature represents that the air mass receives more heat than the local average, suggesting that a large amount of water vapor changes to liquid water or ice and releases latent heat. As a result of that, the droplets in the regions of positive potential temperature anomaly were either larger or denser than the local average (Figs. 8 and 9).

The cross sections of DSD parameters were also different for ECs of the four categories (Figs. 8 and 9). The positive DSD anomalies were the largest in the developing stage (Figs. 8a and 9a), followed by the mature stage (Figs. 8b and 9b), and smallest in the dissipating stage (Figs. 8c and 9c), which was consistent with the results in 

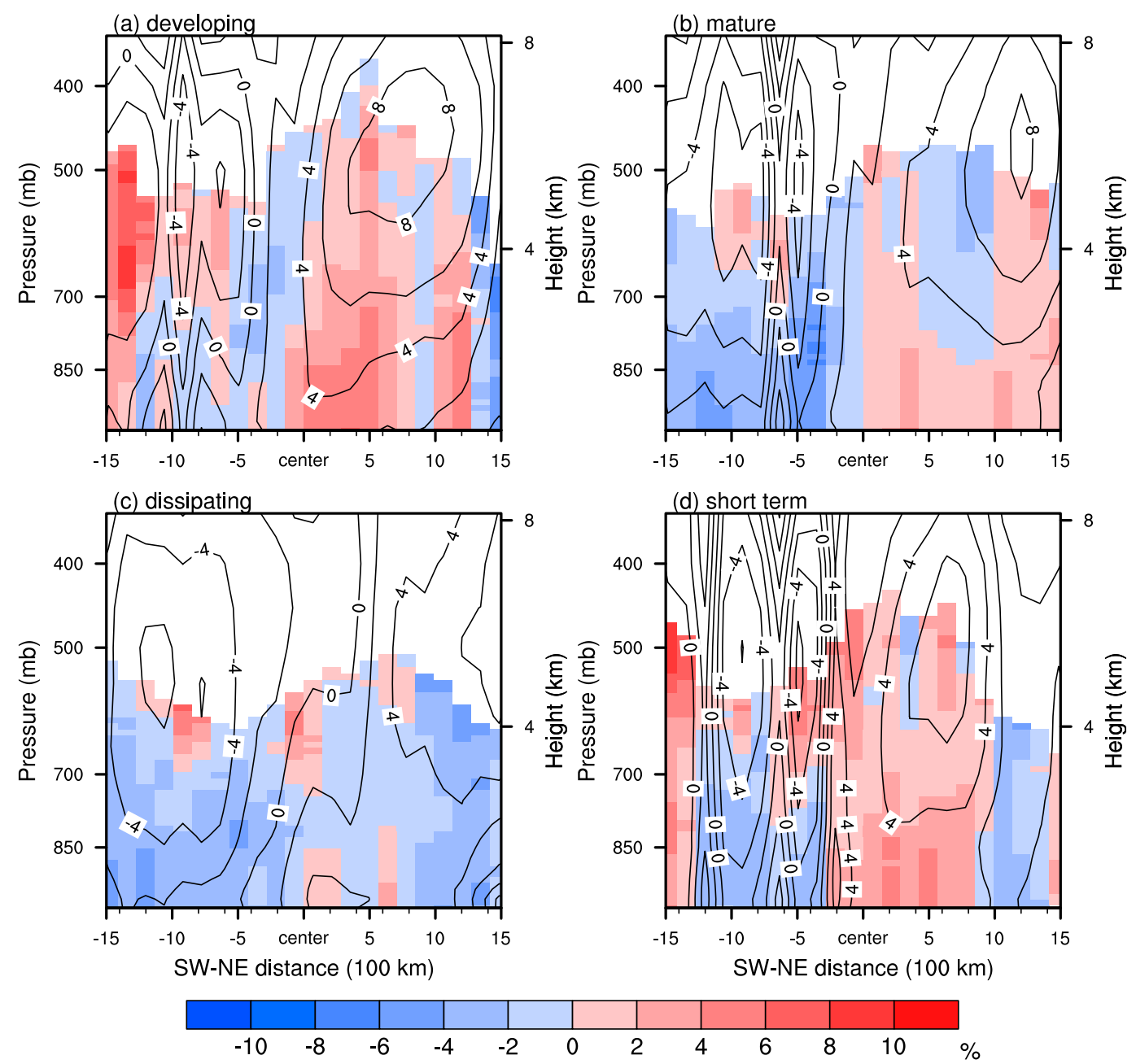

FIG. 9. The southwest-northeast vertical cross section of effective particle diameter $D_{0}$ anomaly for (a) developing ECs, (b) mature ECs, (c) dissipating ECs, and (d) short-term ECs. The contoured lines indicate the potential temperature anomaly $(\mathrm{K})$ relative to the local seasonal average.

Fig. 7. Furthermore, the $N_{0}$ anomaly of the developing stage reached $20 \%$ in the head of comma rainband, while that of the mature stage was less than $0 \%$. This behavior is worthwhile of further investigation, and we think it may be linked with the occluded front in ECs of the mature stage. The cross sections of short-term ECs (Figs. 8d and 9d) were exactly similar to that of the developing stage, further validating that the short-term ECs are incipient ECs but are dying out without entering maturity.

At last, to verify the influence of updraft and water vapor content on the development of EC precipitation, we carried out a correlation analysis of storm-top height anomaly with 850 -hPa vertical velocity and specific humidity for ECs of different life stages (Fig. 10). Our results show that there were significant positive correlations between the storm-top height anomaly and $850-\mathrm{hPa}$ upward vertical velocity or specific humidity for ECs of all stages, and the correlations all passed the $95 \%$ confidence $t$ test. The numerical order of correlation coefficients of each stage also corresponds to that of the near-surface rain rate anomalies (Fig. 7): the largest for the developing stage, followed by the mature stage, and the smallest for the dissipating stage.

\section{Conclusions}

To investigate the precipitation features of ECs in the northern Pacific storm track, we first identified the tracks of ECs using the ERA-Interim MSLP data and then established an EC coordinate system with the origin indicating the center of the ECs. Under this coordinate system, the distribution of precipitation parameters for ECs, including the environmental field, the near-surface rain rate, the radar reflectivity, and the 

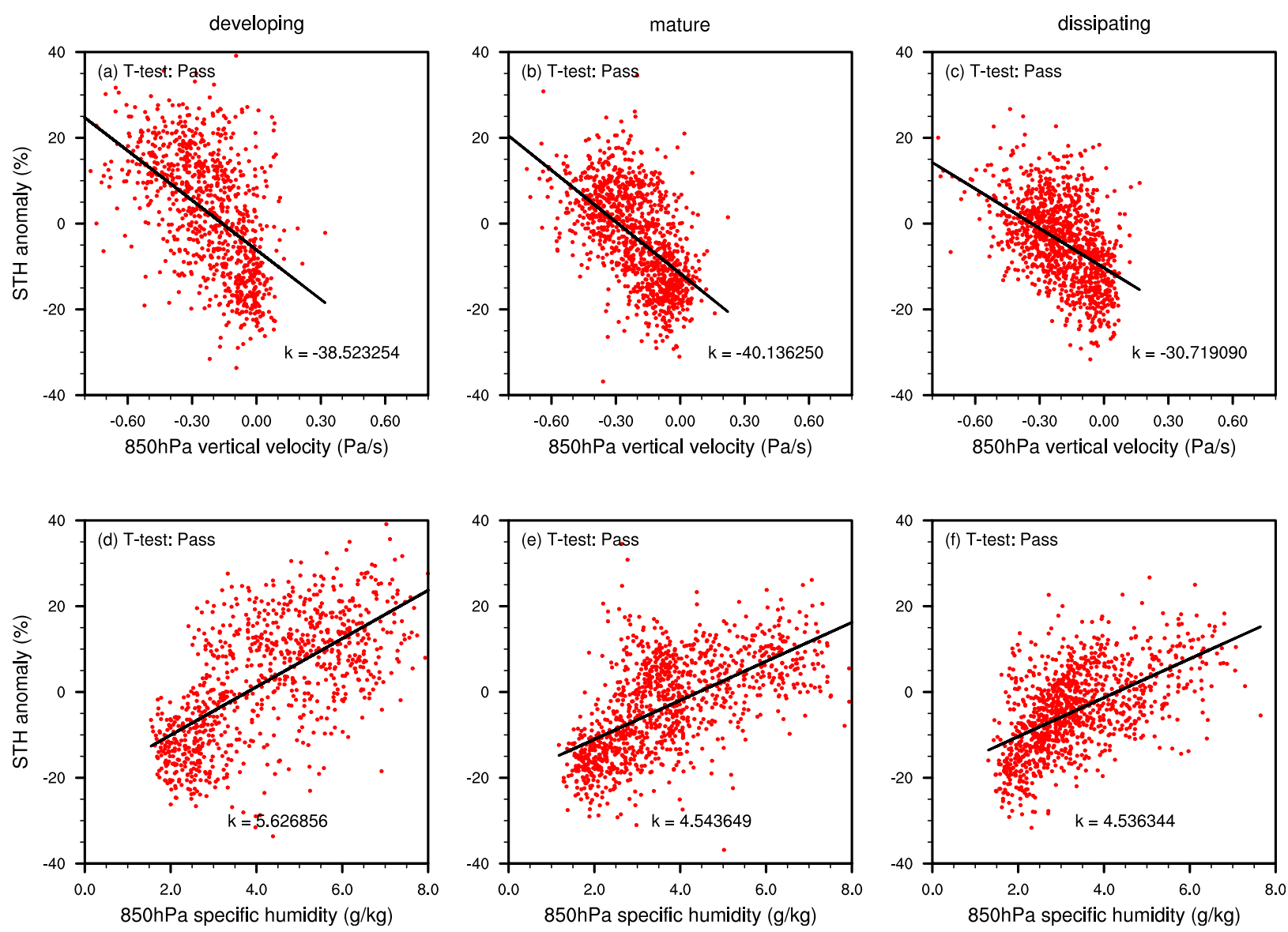

FIG. 10. Scatterplots of (a)-(c) 850-hPa vertical velocity vs storm-top height anomaly and (d)-(f) 850-hPa specific humidity vs storm-top height anomaly for ECs of different life stage. Specifically, the negative vertical velocity indicates that the air mass rises.

droplet size distributions were plotted and the causes of the spatial precipitation distributions were explored.

Consistent with the previously reported results (Carlson 1991; Hoskins and Pedder 1980), the pressure fields accompanying the ECs in the storm-track region were significantly different between the lower troposphere and the mid- to upper troposphere. The pressure field in the lower troposphere showed significant convergence with the lowest air pressure in the center of the EC. The pressure field in the mid- and upper troposphere was low to the northwest, but high to the southeast of the ECs. There were two obvious fronts in the EC structure under this pressure situation. To the southeast of the ECs, where it was surrounded by two fronts, the vertical air motion showed upward motion, whereas downward motion was seen to the northwest of the ECs.

Using the 2ADPR products and the EC coordinate system, we showed a unique comma rainband to the east of ECs. The structure of the ECs had the opposite impact on precipitation to the west and east. The near-surface droplet concentration $N_{0}$, the effective droplet size $D_{0}$, near-surface rain rate, and storm-top height to the east of the ECs increased by $4 \%, 2 \%, 15 \%$, and $5 \%$, respectively, relative to the local seasonal average as a result of the obvious updraft and the moist air brought by the southerly cyclonic circulation. By contrast, the precipitation was weaker and lower than the local seasonal average in the region to the west of the ECs. Our analysis of the Ku-band reflectivity of EC precipitation validated these conclusions.

Considering the structural changes of EC during its life cycle, we also studied the life cycle effects on the precipitation distribution of ECs. ECs were classified into four categories including developing, mature, dissipating, and short-term ECs. ECs of all categories had a comma rainband to the east of the cyclonic center. All types of ECs promoted precipitation to their east while suppressed precipitation to their west. ECs of different life stages had different degrees of impact on precipitation: the highest in the developing stage, followed by the mature stage, and the weakest in the dissipating stage. The precipitation of short-term ECs showed exactly similar properties to that of developing ECs, 
indicating that short-term ECs may be incipient ECs, but they die out without entering maturity. By DSD analysis, we further revealed that regions of positive potential temperature anomalies in the EC coordinate were accompanied by either larger or denser droplets than the local average, and the relations between potential temperature anomalies and DSD parameters were also influenced by the life stage of ECs.

In this manuscript, we have shown that the structure of ECs promotes precipitation to the east, but suppresses precipitation to the west. We should therefore account for the location of precipitation in the structure of ECs in future studies of cyclonic precipitation in the northern Pacific storm-track region. Our results would also be helpful to provide observational evidence for the model of extratropical cyclones.

Acknowledgments. This work is supported by the National Natural Science Foundation of China (NSFC) Project (Grant 91837310, 41675041, and 41620104009), National Key Research and Development Program of China (Grant 2017YFC1501402 and 2018YFC1507200), and Key research and development projects in Anhui province (Grant 201904a07020099).

\section{REFERENCES}

Adler, R. F., G. Gu, M. Sapiano, J. Wang, and G. J. Huffman, 2017: Global precipitation: Means, variations and trends during the satellite era (1979-2014). Surv. Geophys., 38, 679-699, https:// doi.org/10.1007/s10712-017-9416-4.

Bengtsson, L., K. I. Hodges, and E. Roeckner, 2006: Storm tracks and climate change. J. Climate, 19, 3518-3543, https://doi.org/ 10.1175/JCLI3815.1.

Bjerknes, J., 1919: On the structure of moving cyclones. Mon. Wea. Rev., 47, 95-99, https://doi.org/10.1175/1520-0493(1919)47<95: OTSOMC $>2.0 . \mathrm{CO} ; 2$.

— formation of rain. Geofys. Publ., 2, 1-60.

- , and — 1922: Life cycle of cyclones and the polar front theory of atmospheric circulation. Geofys. Publ., 3, 1-18.

Cao, Q., G. Zhang, E. Brandes, T. Schuur, A. Ryzhkov, and K. Ikeda, 2008: Analysis of video disdrometer and polarimetric radar data to characterize rain microphysics in Oklahoma. J. Appl. Meteor. Climatol., 47, 2238-2255, https:// doi.org/10.1175/2008JAMC1732.1.

Carlson, T. N., 1980: Air-flow through mid-latitude cyclones and the comma cloud pattern. Mon. Wea. Rev., 108, 1498-1509, https:// doi.org/10.1175/1520-0493(1980)108<1498:ATMCAT>2.0.CO;2.

_ 1991: Mid-Latitude Weather Systems. Cambridge University Press, 507 pp.

Chang, E. K. M., and Y. F. Fu, 2002: Interdecadal variations in Northern Hemisphere winter storm track intensity. J. Climate, 15, 642-658, https://doi.org/10.1175/1520-0442(2002)015<0642: IVINHW $>2.0 . \mathrm{CO} ; 2$.

$\longrightarrow$, and — 2003: Using mean flow change as a proxy to infer interdecadal storm track variability. J. Climate, 16, 2178-2196, https://doi.org/10.1175/2773.1.
— - Y. Guo, and X. Xia, 2012: CMIP5 multimodel ensemble projection of storm track change under global warming. J. Geophys. Res., 117, D23118, https://doi.org/10.1029/ 2012JD018578.

Chen, Y. L., and Y. F. Fu, 2018: Tropical echo-top height for precipitating clouds observed by multiple active instruments aboard satellites. Atmos. Res., 199, 54-61, https://doi.org/ 10.1016/j.atmosres.2017.08.008.

Dee, D. P., and Coauthors, 2011: The ERA-Interim reanalysis: Configuration and performance of the data assimilation system. Quart. J. Roy. Meteor. Soc., 137, 553-597, https://doi.org/ 10.1002/qj.828.

Field, P. R., and R. Wood, 2007: Precipitation and cloud structure in midlatitude cyclones. J. Climate, 20, 233-254, https:// doi.org/10.1175/JCLI3998.1.

Graff, L. S., and J. H. LaCasce, 2012: Changes in the extratropical storm tracks in response to changes in SST in an AGCM. J. Climate, 25, 1854-1870, https://doi.org/10.1175/JCLI-D-1100174.1.

Hamada, A., and Y. N. Takayabu, 2016: Improvements in detection of light precipitation with the Global Precipitation Measurement Dual-Frequency Precipitation Radar (GPM DPR). J. Atmos. Oceanic Technol., 33, 653-667, https:// doi.org/10.1175/JTECH-D-15-0097.1.

Harvey, B. J., L. C. Shaffrey, and T. J. Woollings, 2015: Deconstructing the climate change response of the Northern Hemisphere wintertime storm tracks. Climate Dyn., 45, 28472860, https://doi.org/10.1007/s00382-015-2510-8.

Hawcroft, M. K., L. C. Shaffrey, K. I. Hodges, and H. F. Dacre, 2012: How much Northern Hemisphere precipitation is associated with extratropical cyclones? Geophys. Res. Lett., 39, L24809, https://doi.org/10.1029/2012GL053866.

Held, I. M., S. W. Lyons, and S. Nigam, 1989: Transients and the extratropical response to El-Nino. J. Atmos. Sci., 46, 163-174, https://doi.org/10.1175/1520-0469(1989)046<0163:TATERT> 2.0.CO;2.

Hobbs, P. V., R. A. Houze, and T. J. Matejka, 1975: Dynamical and microphysical structure of an occluded frontal system and its modification by orography. J. Atmos. Sci., 32, 1542-1562, https://doi.org/10.1175/1520-0469(1975)032<1542:TDAMSO> 2.0.CO;2.

Hoskins, B. J., and M. A. Pedder, 1980: The diagnosis of middle latitude synoptic development. Quart. J. Roy. Meteor. Soc., 106, 707-719, https://doi.org/10.1002/qj.49710645004.

, and P. J. Valdes, 1990: On the existence of storm-tracks. J. Atmos. Sci., 47, 1854-1864, https://doi.org/10.1175/15200469(1990)047<1854:OTEOST>2.0.CO;2.

, and K. I. Hodges, 2005: A new perspective on Southern Hemisphere storm tracks. J. Climate, 18, 4108-4129, https:// doi.org/10.1175/JCLI3570.1.

Hou, A. Y., and Coauthors, 2014: The global precipitation measurement mission. Bull. Amer. Meteor. Soc., 95, 701-722, https://doi.org/10.1175/BAMS-D-13-00164.1.

Houze, R. A., P. V. Hobbs, K. R. Biswas, and W. M. Davis, 1976: Mesoscale rainbands in extratropical cyclones. Mon. Wea. Rev., 104, 868-878, https://doi.org/10.1175/1520-0493(1976) 104<0868:MRIEC > 2.0.CO;2.

— S. S. Chen, B. F. Smull, W. Lee, and M. M. Bell, 2007: Hurricane intensity and eyewall replacement. Science, 315, 1235-1239, https://doi.org/10.1126/science.1135650.

Iguchi, T., and Coauthors, 2012: An overview of the precipitation retrieval algorithm for the Dual-frequency Precipitation Radar (DPR) on the Global Precipitation Measurement 
(GPM) mission's core satellite. Proc. SPIE, 8528, 85281C, https://doi.org/10.1117/12.977352.

Johnson, J. T., P. L. MacKeen, A. Witt, E. D. Mitchell, G. J. Stumpf, M. D. Eilts, and K. W. Thomas, 1998: The storm cell identification and tracking algorithm: An enhanced WSR-88D algorithm. Wea. Forecasting, 13, 263-276, https://doi.org/ 10.1175/1520-0434(1998)013<0263:TSCIAT $>2.0$. CO;2.

Kidston, J., A. A. Scaife, S. C. Hardiman, D. M. Mitchell, N. Butchart, M. P. Baldwin, and L. J. Gray, 2015: Stratospheric influence on tropospheric jet streams, storm tracks and surface weather. Nat. Geosci., 8, 433-440, https://doi.org/10.1038/ngeo2424.

Langmuir, I., 1948: The production of rain by a chain reaction in cumulus clouds at temperatures above freezing. J. Meteor., 5, 175-192, https://doi.org/10.1175/1520-0469(1948)005<0175: TPORBA $>2.0 . \mathrm{CO} ; 2$.

Lau, N. C., 1988: Variability of the observed midlatitude storm tracks in relation to low-frequency changes in the circulation pattern. J. Atmos. Sci., 45, 2718-2743, https://doi.org/10.1175/ 1520-0469(1988)045<2718:VOTOMS>2.0.CO;2.

Lehmann, J., and D. Coumou, 2015: The influence of mid-latitude storm tracks on hot, cold, dry and wet extremesSci. Rep., 5 , 17491, https://doi.org/10.1038/SREP17491.

Li, X., J. A. Zhang, X. Yang, W. G. Pichel, M. DeMaria, D. Long, and Z. Li, 2013: Tropical cyclone morphology from spaceborne synthetic aperture radar. Bull. Amer. Meteor. Soc., 94, 215-230, https://doi.org/10.1175/BAMS-D-11-00211.1.

Mace, G. G., 2010: Cloud properties and radiative forcing over the maritime storm tracks of the Southern Ocean and North Atlantic derived from A-Train. J. Geophys. Res., 115, D10201, https://doi.org/10.1029/2009JD012517.

O'Gorman, P. A., 2010: Understanding the varied response of the extratropical storm tracks to climate change. Proc. Natl. Acad. Sci. USA, 107, 19176-19 180, https://doi.org/10.1073/ pnas.1011547107.

Palmen, E., and C. W. Newton, 1969: Atmospheric Circulation System. Academic Press, 603 pp.

Pfahl, S., and M. Sprenger, 2016: On the relationship between extratropical cyclone precipitation and intensity. Geophys. Res. Lett., 43, 1752-1758, https://doi.org/10.1002/2016GL068018.
Pinto, J. G., T. Spangehl, U. Ulbrich, and P. Speth, 2005: Sensitivities of a cyclone detection and tracking algorithm: Individual tracks and climatology. Meteor. Z., 14, 823-838, https://doi.org/10.1127/0941-2948/2005/0068.

Romanić, D., M. Ćurić, M. Lompar, and I. Jovičić, 2016: Contributing factors to Koshava wind characteristics. Int. J. Climatol., 36, 956-973, https://doi.org/10.1002/joc.4397.

Schemm, S., and H. Wernli, 2014: The linkage between the warm and cold conveyor belts in an idealized extratropical cyclone. J. Atmos. Sci., 71, 1443-1459, https://doi.org/10.1175/JAS-D13-0177.1.

Schultz, D. M., 2001: Reexamining the cold conveyor belt. Mon Wea. Rev., 129, 2205-2225, https://doi.org/10.1175/15200493(2001)129<2205:RTCCB > 2.0.CO;2.

_- and G. Vaughan, 2011: Occluded fronts and the occlusion process: A fresh look at conventional wisdom. Bull. Amer. Meteor. Soc., 92, 443-466, https://doi.org/10.1175/ 2010BAMS3057.1.

Shapiro, M. A., and D. Keyser, 1990: Fronts, jet streams and the tropopause. Extratropical Cyclones, C. W. Newton and E. O. Holopainen, Eds., Springer, 167-191.

Shaw, T. A., and Coauthors, 2016: Storm track processes and the opposing influences of climate change. Nat. Geosci., 9, 656664, https://doi.org/10.1038/ngeo2783.

Ulbrich, C. W., and D. Atlas, 2007: Microphysics of raindrop size spectra: Tropical continental and maritime storms. J. Appl. Metorol. Climatol., 46, 1777-1791, https://doi.org/ 10.1175/2007JAMC1649.1.

Yin, J. H., 2005: A consistent poleward shift of the storm tracks in simulations of 21st century climate. Geophys. Res. Lett., 32, L18701, https://doi.org/10.1029/2005GL023684.

Zhang, A., and Y. Fu, 2018: Life cycle effects on the vertical structure of precipitation in East China measured by Himawari-8 and GPM DPR. Mon. Wea. Rev., 146, 21832199, https://doi.org/10.1175/MWR-D-18-0085.1.

- - - Y. Chen, G. Liu, and X. Zhang, 2018: Impact of the surface wind flow on precipitation characteristics over the southern Himalayas: GPM observations. Atmos. Res., 202, 10 22, https://doi.org/10.1016/j.atmosres.2017.11.001. 